\title{
Divine Design or Malevolent Fate
}

\author{
David Denison \\ Royal Brompton Hospital, London, UK
}

Many doctors think God erred when he made airway muscles but others, including David Blyth who writes in this issue of Respiration [1], believe airway muscles normally provide more benefit than harm. Studies on the lungs of marine mammals support the latter view, because their airways are reinforced with cartilage and muscle all the way to the alveoli. The puzzle is this: in marine mammals the muscles appear to keep the airway open but, in terrestrial mammals, Dr. Blyth argues their beneficial role is to constrict. Could both statements be true?

In terrestrial mammals, including shallow divers such as beavers, otters and hippopotami, the airways are floppier than the alveoli they serve and so collapse before the alveoli are empty $[2,3]$. Hence our residual volumes exist and increase as airways are weakened by age or disease. Dr. Blyth in his clear and enjoyable paper claims that the normal, i.e. appropriate, functions of airway muscle are to narrow the airways and so facilitate the expulsion of unwanted material, and to shorten the tracheo-bronchial tree, aiding expiration.

Marine mammals come from very diverse evolutionary roots but all have airways that are stronger than the alveoli they serve, ensuring complete alveolar collapse as they dive below a depth of $30 \mathrm{~m}$ or so. This shunts alveolar gas away from pulmonary capillary blood, neatly avoiding the risks of nitrogen narcosis, oxygen toxicity and decompression illness, that plague man, the only deep-diving terrestrial mammal.

\begin{tabular}{ll}
\hline KARGER & (c) 2001 S. Karger AG, Basel \\
Fax +41 61 306 1234 & $0025-7931 / 01 / 0682-0133 \$ 17.50 / 0$ \\
$\begin{array}{l}\text { E-Mail karger@karger.ch } \\
\text { www.karger.com }\end{array}$ & $\begin{array}{l}\text { Accessible online at: } \\
\text { www.karger.com/journals/res }\end{array}$
\end{tabular}

It is possible that both views of appropriate functions are true. Think of the muscles as a cylindrical geodetic mesh, as if designed by Buckminster Fuller. When shortening of the cylinder is opposed the mesh would contract isometrically, strengthening the walls. When shortening of the cylinder is permitted the mesh contracts isotonically, constricting the walls. It is possible that both functions are appropriate and could even be exercised sequentially in a single breath.

It is certain that some aspects of airway function are inappropriate in asthma. It may also turn out that the temporally and spatially blunderbuss methods used to study airway muscle function in asthma are inappropriate to the examination of the normal functions Dr. Blyth has elegantly brought to mind.

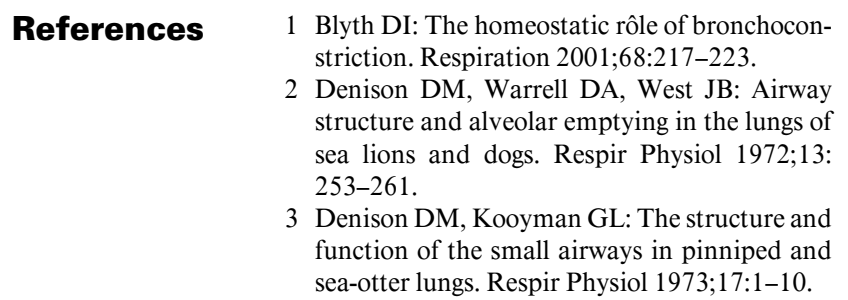

David Denison, Emeritus Professor of Clinical Physiology

Royal Brompton Hospital

Sydney Street

London SW3 6NP London (UK) 